\title{
Self-Rated Physical Health Among Working-Aged Adults Along the Rural-Urban Continuum — United States, 2021
}

\author{
Danielle C. Rhubart, $\mathrm{PhD}^{1}$; Shannon M. Monnat, $\mathrm{PhD}^{2}$
}

Poor self-rated physical health is strongly associated with morbidity and premature mortality $(1,2)$. Studies that are now a decade old report worse self-rated health among rural than among urban residents $(3,4)$. Whether the rural disadvantage persists in 2021 is uncertain and the contributing factors to contemporary rural-urban variations in self-rated health are not known. Rural America is diverse by population size and adjacency to metropolitan areas, and rural populations vary demographically and socioeconomically. This analysis used data from the National Well-being Survey (NWS), a national sample of approximately 4,000 U.S. working-aged adults conducted during February and March 2021 to examine differences in selfrated physical health among residents of large urban; medium/ small urban; metro-adjacent rural; and remote rural counties. Residents of medium/small urban, metro-adjacent rural, and remote rural counties had significantly higher probabilities of reporting fair/poor self-rated physical health than their large urban county peers. There were no significant differences by sex or race/ethnicity in self-rated physical health. Individuallevel socioeconomic resources (including higher educational attainment, higher household income, and higher probability of employment) contributed to the advantage among residents of large urban counties. Although there is no single solution to reducing rural-urban health disparities, these findings suggest that reducing socioeconomic disparities is essential.

NWS is a national, cross-sectional, web-based survey of U.S. adults aged 18-64 years (working-aged adults). The survey was created and administered by the Syracuse University Lerner Center for Public Health Promotion during February and March of 2021. Recruitment was conducted by Qualtrics Panels, which uses a database of several million U.S. adults to recruit survey participants through nonprobability sampling.* Data collection included an oversample of rural residents to enable robust analyses. Poststratification demographic weights were used to allow generalizability to the broader U.S. workingaged population. Weights account for differential response by

\footnotetext{
* Qualtrics Panels owns a database that includes data from several million U.S. adults who have agreed to participate in surveys. Participants are recruited using website intercept recruitment, member referrals, targeted email lists, gaming sites, customer loyalty web portals, permission-based networks, and social media. Names, addresses, and dates of birth are typically validated via third partyverification. For NWS data collection, panel members received an invitation with a hyperlink to NWS. Respondents were compensated in several different ways (e.g., airline miles or gift cards).
}

\section{INSIDE}

167 Association Between Social Vulnerability and Rates of HIV Diagnoses Among Black Adults, by Selected Characteristics and Region of Residence - United States, 2018

171 COVID-19 Vaccination Coverage and Vaccine Confidence by Sexual Orientation and Gender Identity United States, August 29-October 30, 2021

177 SARS-CoV-2 Infection and Hospitalization Among Adults Aged $\geq 18$ Years, by Vaccination Status, Before and During SARS-CoV-2 B.1.1.529 (Omicron) Variant Predominance - Los Angeles County, California, November 7, 2021-January 8, 2022

182 Notes from the Field: COVID-19 Vaccination Among Persons Living with Diagnosed HIV Infection New York, October 2021

186 QuickStats

Continuing Education examination available at https://www.cdc.gov/mmwr/mmwr_continuingEducation.html

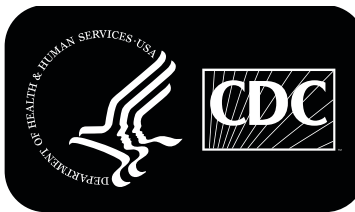


age, race/ethnicity, sex, educational attainment, and ruralurban residence. The NWS completion rate (i.e., completed surveys among those who viewed the landing page and the informed consent section) was $40.4 \%$.

In addition to a standard set of demographic and socioeconomic questions, respondents were asked to answer the following standard self-rated physical health question: "In general, would you say your physical health is excellent, very good, good, fair, or poor?" Responses were dichotomized into fair/poor versus good, very good, or excellent. Survey responses were linked to county-level rural-urban continuum codes (RUCCs) from the U.S. Department of Agriculture Economic Research Service using county Federal Information Processing Standards codes. ${ }^{\dagger}$ RUCCs were recoded into four categories: large urban counties (RUCC 1), medium/small urban counties (RUCCs 2 and 3), metro-adjacent rural counties (RUCCs 4, 6, and 8 ), and remote rural counties (i.e., not adjacent to a metro area) (RUCCs 5, 7, and 9). ${ }^{\$}$ The recoded RUCC categories were used as the primary independent variable. Individuallevel covariates included sex, age, race/ethnicity, marital status, household income, education, health insurance coverage,

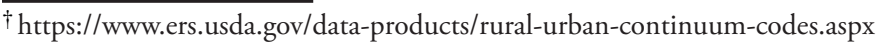

${ }^{\$}$ Large urban counties are those in metropolitan areas of $\geq 1$ million persons; medium/small urban counties are those in metropolitan areas of $<1$ million persons; metro-adjacent rural counties are those that are not in but adjacent to a metropolitan area; rural remote counties are those that are not in or adjacent to metropolitan areas.
}

and employment status.9 Given that data collection occurred approximately 1 year into the COVID-19 pandemic, models also control for respondents' perceived impact of COVID-19 on their lives.

Among 4,014 persons in the original sample, 167 participants had missing information on variables of interest and their data were not used, resulting in a final analytic sample of 3,847. Descriptive statistics for self-rated physical health and model covariates are reported by rural-urban status. Logistic regression analyses predicting self-reported fair/poor physical health with clustered standard errors for states were used to calculate predicted probabilities of fair/poor physical health as a function of the rural-urban continuum and individual-level characteristics. All analyses were weighted with the poststratification weight and conducted using SAS software (version 9.4; SAS Institute). NWS survey and recruitment design were approved by the Syracuse University Institutional Review Board.

In the weighted sample of U.S. working-aged adults, the prevalence of reporting fair/poor physical health was significantly higher in medium/small urban $(31.1 \%)$, metro-adjacent rural $(40.2 \%)$, and remote rural $(34.0 \%)$ counties than in large urban counties $(23.4 \%)$ (Table 1$)$. Rural-urban variation in

\footnotetext{
Respondents could select all that apply for the employment status question. Responses were recoded into four mutually exclusive groups: all those who indicated any disability; those who indicated unemployment, but no disability; those who indicated employment but no disability or unemployment; and those who did not indicate unemployment, employment, or disability (i.e., retired, homemakers, or students).
}

The MMWR series of publications is published by the Center for Surveillance, Epidemiology, and Laboratory Services, Centers for Disease Control and Prevention (CDC), U.S. Department of Health and Human Services, Atlanta, GA 30329-4027.

Suggested citation: [Author names; first three, then et al., if more than six.] [Report title]. MMWR Morb Mortal Wkly Rep 2022;71:[inclusive page numbers].

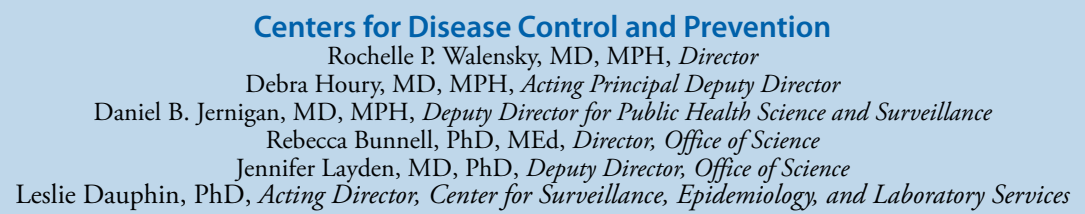

MMWR Editorial and Production Staff (Weekly)

Charlotte K. Kent, PhD, MPH, Editor in Chief Jacqueline Gindler, MD, Editor

Paul Z. Siegel, MD, MPH, Associate Editor

Mary Dott, MD, MPH, Online Editor

Terisa F. Rutledge, Managing Editor

Teresa M. Hood, MS, Lead Technical Writer-Editor

Leigh Berdon, Glenn Damon, Soumya Dunworth, PhD,

Tiana Garrett-Cherry, PhD, MPH, Srila Sen, MA, Stacy Simon, MA, Morgan Thompson, Technical Writer-Editors

Matthew L. Boulton, MD, MPH

Carolyn Brooks, $\mathrm{ScD}$, MA

Jay C. Butler, MD

Virginia A. Caine, MD

Jonathan E. Fielding, MD, MPH, MBA

David W. Fleming, MD
Martha F. Boyd, Lead Visual Information Specialist Alexander J. Gottardy, Maureen A. Leahy,

Julia C. Martinroe, Stephen R. Spriggs, Tong Yang, Visual Information Specialists

Quang M. Doan, MBA, Phyllis H. King, Terraye M. Starr, Moua Yang, Information Technology Specialists
Ian Branam, MA,

Acting Lead Health Communication Specialist Shelton Bartley, MPH, Leslie Hamlin,

Lowery Johnson, Amanda Ray,

Health Communication Specialists Will Yang, MA,

Visual Information Specialist

\section{MMWR Editorial Board}

Timothy F. Jones, MD, Chairman

William E. Halperin, MD, DrPH, MPH

Jewel Mullen, MD, MPH, MPA

Jeff Niederdeppe, PhD

Celeste Philip, MD, MPH

Patricia Quinlisk, MD, MPH

Patrick L. Remington, MD, MPH
Carlos Roig, MS, MA

William Schaffner, MD

Nathaniel Smith, MD, MPH

Morgan Bobb Swanson, BS

Abbigail Tumpey, MPH 
several characteristics that might drive the observed variation in self-rated physical health was observed. Compared demographically with residents of large urban counties, those residing in metro-adjacent rural and remote rural counties were more likely to be female, older, and non-Hispanic White. In terms of socioeconomic differences, residents of metro-adjacent and remote rural counties were significantly more likely than residents of large urban counties to be on disability, have a high school diploma or less, be uninsured, and have annual household incomes $<\$ 25,000$.

Predicted probabilities of self-rated fair/poor physical health in the fully adjusted model indicate that the differences between large urban, medium/small urban, and remote rural counties were no longer statistically significant; however, a significantly higher probability of reporting fair/poor health persisted among residents of metro-adjacent rural counties
(Table 2). Stepwise regression models demonstrated that the remote rural disadvantage observed in the unadjusted model is associated with lower income, lower educational attainment, and higher rates of disability in remote rural counties compared with those in large urban counties.

Several other characteristics were also associated with likelihood of self-reporting fair/poor health. Adjusted probabilities were higher among the following comparison groups: those who were unemployed $(37.6 \%)$ or on disability $(66.8 \%)$ versus those who were employed (18.3\%), those with a high school diploma or less $(35.0 \%)$ and some college $(35.1 \%)$ versus those with a bachelor's degree or more (14.9\%), and those with household income $<\$ 25,000(41.2 \%)$ or $\$ 25,000-\$ 49,999(36.1 \%)$ versus those with household income $\geq \$ 50,000(15.4 \%)$.

TABLE 1. Characteristics of U.S. adults aged 18-64 years, by rural-urban status* - National Well-being Survey, United States, 2021

\begin{tabular}{|c|c|c|c|c|c|c|}
\hline \multirow[b]{2}{*}{ Characteristic } & \multicolumn{5}{|c|}{ County classification (weighted unadjusted \%) } & \multirow[b]{2}{*}{ p-value } \\
\hline & $\begin{array}{c}\text { Large urban } \\
(n=1,770)\end{array}$ & $\begin{array}{l}\text { Medium/Small urban } \\
\qquad(\mathrm{n}=985)\end{array}$ & $\begin{array}{l}\text { Metro-adjacent rural } \\
\quad(n=687)\end{array}$ & $\begin{array}{c}\text { Remote rural } \\
(n=405)\end{array}$ & $\begin{array}{l}\text { Chi-square } \\
\text { statistic }\end{array}$ & \\
\hline $\begin{array}{l}\text { Self-rated physical health } \\
\text { Fair/Poor }\end{array}$ & 23.4 & 31.1 & 40.2 & 34.0 & 57.3 & $<0.001$ \\
\hline $\begin{array}{l}\text { Sex } \\
\text { Female }\end{array}$ & 45.3 & 54.1 & 62.0 & 62.7 & 57.9 & $<0.001$ \\
\hline $\begin{array}{l}\text { Age group, yrs } \\
18-29 \\
30-49 \\
50-64\end{array}$ & $\begin{array}{l}23.5 \\
46.1 \\
30.5\end{array}$ & $\begin{array}{l}24.1 \\
40.7 \\
35.3\end{array}$ & $\begin{array}{l}20.3 \\
41.3 \\
38.3\end{array}$ & $\begin{array}{l}18.0 \\
48.5 \\
33.5\end{array}$ & 19.0 & 0.004 \\
\hline $\begin{array}{l}\text { Race/Ethnicity } \\
\text { White, non-Hispanic } \\
\text { Black, non-Hispanic } \\
\text { Hispanic } \\
\text { Other race }\end{array}$ & $\begin{array}{r}53.5 \\
14.5 \\
22.9 \\
9.1\end{array}$ & $\begin{array}{r}63.7 \\
13.0 \\
16.0 \\
7.3\end{array}$ & $\begin{array}{r}87.0 \\
3.9 \\
5.0 \\
4.2\end{array}$ & $\begin{array}{r}85.1 \\
4.5 \\
6.0 \\
4.4\end{array}$ & 202.9 & $<0.001$ \\
\hline $\begin{array}{l}\text { Marital status } \\
\text { Not married }\end{array}$ & 55.8 & 58.7 & 58.3 & 56.4 & 2.7 & 0.564 \\
\hline $\begin{array}{l}\text { Employment status } \\
\text { Employed } \\
\text { Unemployed } \\
\text { Disability } \\
\text { Retired/Homemaker/Student }\end{array}$ & $\begin{array}{r}61.0 \\
16.0 \\
6.5 \\
16.5\end{array}$ & $\begin{array}{l}52.6 \\
17.6 \\
10.4 \\
19.3\end{array}$ & $\begin{array}{l}44.8 \\
17.1 \\
16.3 \\
21.9\end{array}$ & $\begin{array}{l}45.2 \\
17.6 \\
15.1 \\
22.0\end{array}$ & 78.2 & $<0.001$ \\
\hline $\begin{array}{l}\text { Educational attainment } \\
\text { Bachelor's degree or more } \\
\text { Some college } \\
\text { High school diploma or less }\end{array}$ & $\begin{array}{l}39.0 \\
29.0 \\
32.0\end{array}$ & $\begin{array}{l}25.3 \\
33.4 \\
41.3\end{array}$ & $\begin{array}{l}17.3 \\
32.2 \\
50.5\end{array}$ & $\begin{array}{l}19.8 \\
32.5 \\
47.8\end{array}$ & 129.8 & $<0.001$ \\
\hline $\begin{array}{l}\text { Health insurance } \\
\text { Uninsured }\end{array}$ & 15.5 & 21.4 & 24.4 & 19.5 & 28.1 & $<0.001$ \\
\hline $\begin{array}{l}\text { Household income, USD } \\
\geq 50,000 \\
25,000-49,999 \\
<25,000 \\
\text { Not reported }\end{array}$ & $\begin{array}{r}50.2 \\
22.6 \\
22.6 \\
3.6\end{array}$ & $\begin{array}{r}38.4 \\
25.3 \\
32.3 \\
4.1\end{array}$ & $\begin{array}{r}30.7 \\
27.5 \\
39.9 \\
2.0\end{array}$ & $\begin{array}{r}27.0 \\
27.2 \\
42.2 \\
3.5\end{array}$ & 127.4 & $<0.001$ \\
\hline
\end{tabular}

Abbreviation: USD = U.S. dollars.

* Large urban counties are those in metropolitan areas of $\geq 1$ million persons; medium/small urban counties are those in metropolitan areas of $<1$ million persons; metro-adjacent rural counties are those that are not in, but adjacent to, a metropolitan area; rural remote counties are those that are not in or adjacent to metropolitan areas. 
TABLE 2. Characteristics of U.S. adults aged 18-64 years, by unadjusted and adjusted probabilities of reporting fair/poor physical health* National Well-being Survey, United States, 2021

\begin{tabular}{|c|c|c|c|c|c|}
\hline \multirow[b]{2}{*}{ Characteristic } & \multirow[b]{2}{*}{ No. } & \multicolumn{2}{|c|}{ Unadjusted } & \multicolumn{2}{|c|}{ Adjusted } \\
\hline & & $\%$ & $p$-value & $\%$ & $p$-value \\
\hline Overall & 3,847 & 29.5 & $<0.001$ & 27.4 & $<0.001$ \\
\hline $\begin{array}{l}\text { Rural-urban status }{ }^{\dagger} \\
\text { Large urban } \\
\text { Medium/Small urban } \\
\text { Metro-adjacent rural } \\
\text { Remote rural }\end{array}$ & $\begin{array}{r}1,770 \\
985 \\
687 \\
405\end{array}$ & $\begin{array}{l}23.4 \\
31.1 \\
40.2 \\
34.0\end{array}$ & $\begin{array}{r}\text { Ref } \\
<0.001 \\
<0.001 \\
<0.001\end{array}$ & $\begin{array}{l}21.7 \\
28.9 \\
37.5 \\
31.6\end{array}$ & $\begin{array}{r}\text { Ref } \\
0.083 \\
0.018 \\
0.575\end{array}$ \\
\hline $\begin{array}{l}\text { Sex } \\
\text { Male } \\
\text { Female }\end{array}$ & $\begin{array}{l}1,897 \\
1,950\end{array}$ & - & - & $\begin{array}{l}23.1 \\
32.0\end{array}$ & $\begin{array}{r}\text { Ref } \\
0.205\end{array}$ \\
\hline $\begin{array}{l}\text { Age group, yrs } \\
18-29 \\
30-49 \\
50-64\end{array}$ & $\begin{array}{r}882 \\
1,732 \\
1,233\end{array}$ & $\begin{array}{l}- \\
- \\
-\end{array}$ & $\begin{array}{l}- \\
- \\
-\end{array}$ & $\begin{array}{l}26.9 \\
24.7 \\
31.5\end{array}$ & $\begin{array}{r}\text { Ref } \\
0.562 \\
0.407\end{array}$ \\
\hline $\begin{array}{l}\text { Race/Ethnicity } \\
\text { White, non-Hispanic } \\
\text { Black, non-Hispanic Black } \\
\text { Hispanic } \\
\text { Other }\end{array}$ & $\begin{array}{r}2,339 \\
494 \\
710 \\
304\end{array}$ & $\begin{array}{l}- \\
- \\
-\end{array}$ & $\begin{array}{l}- \\
- \\
-\end{array}$ & $\begin{array}{l}28.0 \\
25.9 \\
27.8 \\
24.0\end{array}$ & $\begin{array}{r}\text { Ref } \\
0.076 \\
0.826 \\
0.871\end{array}$ \\
\hline $\begin{array}{l}\text { Marital status } \\
\text { Married } \\
\text { Not married }\end{array}$ & $\begin{array}{l}1,730 \\
2,117\end{array}$ & - & - & $\begin{array}{l}20.6 \\
33.0\end{array}$ & $\begin{array}{r}\text { Ref } \\
0.079\end{array}$ \\
\hline $\begin{array}{l}\text { Employment status } \\
\text { Employed } \\
\text { Unemployed } \\
\text { On disability } \\
\text { Retired/Homemaker/Student }\end{array}$ & $\begin{array}{r}2,268 \\
567 \\
344 \\
668\end{array}$ & $\begin{array}{l}- \\
- \\
-\end{array}$ & $\begin{array}{l}- \\
- \\
-\end{array}$ & $\begin{array}{l}18.3 \\
37.6 \\
66.8 \\
29.4\end{array}$ & $\begin{array}{r}\text { Ref } \\
<0.001 \\
<0.001 \\
0.002\end{array}$ \\
\hline $\begin{array}{l}\text { Educational attainment } \\
\text { Bachelor's degree or more } \\
\text { Some college } \\
\text { High school degree or less }\end{array}$ & $\begin{array}{l}1,459 \\
1,263 \\
1,125\end{array}$ & $\begin{array}{l}- \\
- \\
-\end{array}$ & $\begin{array}{l}- \\
- \\
-\end{array}$ & $\begin{array}{l}14.9 \\
35.1 \\
35.0\end{array}$ & $\begin{array}{r}\text { Ref } \\
<0.001 \\
<0.001\end{array}$ \\
\hline $\begin{array}{l}\text { Health insurance } \\
\text { Insured } \\
\text { Uninsured }\end{array}$ & $\begin{array}{r}3,182 \\
665\end{array}$ & - & - & $\begin{array}{l}26.7 \\
30.5\end{array}$ & $\begin{array}{r}\text { Ref } \\
0.994\end{array}$ \\
\hline $\begin{array}{l}\text { Income, USD } \\
\geq 50,000 \\
25,000-49,999 \\
<25,000 \\
\text { Not reported } \\
\text { c-statistic } \\
\end{array}$ & $\begin{array}{r}1,777 \\
901 \\
1,040 \\
129 \\
-\end{array}$ & $\begin{array}{l}- \\
- \\
- \\
0.57\end{array}$ & $\begin{array}{l}- \\
- \\
-\end{array}$ & $\begin{array}{l}15.4 \\
36.1 \\
41.2 \\
20.8 \\
0.74\end{array}$ & $\begin{array}{r}\text { Ref } \\
<0.001 \\
<0.001 \\
0.747 \\
-\end{array}$ \\
\hline
\end{tabular}

Abbreviations: Ref = referent group; USD = U.S. dollars.

* Logistic regression models are weighted and control for respondents' self-report of impact of the COVID-19 pandemic on their lives and adjusted for clustered SEs for states.

† Large urban counties are those in metropolitan areas of $\geq 1$ million persons; medium/small urban counties are those in metropolitan areas of $<1$ million persons; metro-adjacent rural counties are those that are not in, but adjacent to, a metropolitan area; rural remote counties are those that are not in or adjacent to metropolitan areas.

$\S$ The c-statistic is a measure of goodness of fit for binary outcomes and ranges from 0.5 to 1.0.

\section{Discussion}

Several important findings emerge from these analyses. Large differences in self-reported physical health exist among working-aged adults in the United States along the rural-urban continuum. Residents of medium/small urban, metro-adjacent rural, and remote rural counties are significantly more likely to self-rate their physical health as fair/poor than are residents of large urban counties. Given that self-rated health has been determined to be strongly associated with chronic health conditions and premature mortality, the limited city and rural disadvantage portends broader consequences for population health disparities. Recent studies report a large and growing rural mortality penalty (i.e., the long running trend of higher mortality rates in rural areas compared with those in urban areas) (5). A recent report from the National Academies of Sciences, Engineering, and Medicine $(\sigma)$ found that recent working-aged mortality increases have been most pronounced outside of large metropolitan areas. Adjusted models indicated 


\section{Summary}

What is already known about this topic?

Self-rated physical health is strongly associated with morbidity and premature mortality. Decade-old studies report worse self-rated health among rural residents, but no recent reports exist on current rural-urban differences.

What is added by this report?

During 2021, working-aged adults in small/medium urban counties and rural counties reported worse physical health compared with residents of large urban counties. These differences are largely explained by differences in socioeconomic status (including lower educational attainment, household income, and probability of employment).

What are the implications for public health practice?

Policies addressing intersecting socioeconomic factors, including those that increase access to livable wage jobs, especially for those without a college degree, likely would reduce rural-urban health disparities.

that socioeconomic factors (e.g., lower education, lower income, lower rates of health insurance coverage, and lower levels of employment) account for much of the remote rural disadvantage in self-reported health. These findings are consistent with fundamental cause theory, wherein socioeconomic status affects disease outcomes through multiple risk pathways over time ( 7 ) and align with previous work illustrating a rural disadvantage in self-rated health that is in part tied to ruralurban differences in sociodemographic characteristics $(3,4)$. The persistent metro-adjacent rural disadvantage might speak to the fact that counties in this category are more likely to be located in the South where a myriad of macro and structural factors produce worse health outcomes (e.g., lower access to care and higher place-level poverty rates) (8).

The findings in this report are subject to at least three limitations. First, the data are cross-sectional, and causality should not be inferred. Second, the data were collected approximately 1 year into the COVID-19 pandemic. Reports of self-rated physical health might have been affected by pandemic-related impacts. The models control for respondents' self-perceived impact of the pandemic on their lives, but the findings should be viewed in the context of this enduring public health disruption. Finally, the sample is based on an opt-in web panel. Pew Research Center recently compared survey response estimates on 406 survey items for mail versus Internet-based responses and found that estimates differed by $\geq 5$ percentage points on only nine items, all having to do with Internet access. Their report concluded that coverage bias associated with web surveys is modest for most kinds of measures (9).
A large body of research demonstrates that multiple factors are responsible for the worse rural health profile in the United States, suggesting that multiple policy strategies will be needed to address these disparities $(5,6)$. Policies focused on reducing socioeconomic disparities, such as increasing the availability of livable wage jobs, especially for persons without a college degree, likely would address poor health outcomes in rural areas.

Corresponding author: Danielle C. Rhubart, dcr185@psu.edu, 814-863-7256.

\footnotetext{
${ }^{1}$ Department of Biobehavioral Health, The Pennsylvania State University, State College, Pennsylvania; ${ }^{2}$ Lerner Center for Public Health Promotion and Department of Sociology, Syracuse University, Syracuse, New York.
}

All authors have completed and submitted the International Committee of Medical Journal Editors form for disclosure of potential conflicts of interest. Danielle C. Rhubart and Shannon M. Monnat report infrastructural support from the Population Research Institute at The Pennsylvania State University, which receives center funding from the Eunice Kennedy Shriver National Institute of Child Health and Human Development, National Institutes of Health (NIH); infrastructural support from the Lerner Center for Public Health Promotion; network support from the Interdisciplinary Network on Rural Population Health and Aging (INRPHA), funded by the National Institute on Aging, NIH; and research network support from the U.S. Department of Agriculture Agricultural Experiment Station Multistate Research Project, W4001: Social, Economic, and Environmental Causes and Consequences of Demographic Change in Rural America. Danielle C. Rhubart also reports pilot grant funding from INRPHA. Shannon M. Monnat reports research grant funding from the National Institute on Aging and research infrastructure support from the Syracuse University Center for Aging and Policy Studies, which received center funding from the National Institute on Aging, NIH. No other potential conflicts of interest were disclosed.

\section{References}

1. Latham K, Peek CW. Self-rated health and morbidity onset among late midlife US adults. J Gerontol B Psychol Sci Soc Sci 2013;68:107-16. PMID:23197340 https://doi.org/10.1093/geronb/gbs104

2. Reile R, Stickley A, Leinsalu M. Large variation in predictors of mortality by levels of self-rated health: results from an 18-year follow-up study. Public Health 2017;145:59-66. PMID:28359392 https://doi. org/10.1016/j.puhe.2016.12.034

3. Monnat SM, Beeler Pickett C. Rural/urban differences in self-rated health: examining the roles of county size and metropolitan adjacency. Health Place 2011;17:311-9. PMID:21159541 https://doi.org/10.1016/j. healthplace.2010.11.008

4. Bethea TN, Lopez RP, Cozier YC, White LF, McClean MD. The relationship between rural status, individual characteristics, and self-rated health in the Behavioral Risk Factor Surveillance System. J Rural Health 2012;28:327-38. PMID:23083079 https://doi. org/10.1111/j.1748-0361.2012.00414.x

5. Cosby AG, McDoom-Echebiri MM, James W, Khandekar H, Brown W, Hanna HL. Growth and persistence of place-based mortality in the United States: the rural mortality penalty. Am J Public Health 2019;109:155-62. PMID:30496008 https://doi.org/10.2105/AJPH.2018.304787 
6. National Academies of Sciences, Engineering, and Medicine. High and rising mortality rates among working-age adults. Washington, DC: The National Academies Press; 2021.

7. Link BG, Phelan J. Social conditions as fundamental causes of disease. J Health Soc Behav 1995;35:80-94. PMID:7560851 https://doi. org/10.2307/2626958
8. Miller CE, Vasan RS. The southern rural health and mortality penalty: a review of regional health inequities in the United States. Soc Sci Med 2021;268:113443. PMID:33137680 https://doi.org/10.1016/j. socscimed.2020.113443

9. Keeter S, McGeeney K. Coverage error in internet surveys: who web-only surveys miss and how that affects results. Pew Research Center; 2015. https://www.pewresearch.org/methods/2015/09/22/ coverage-error-in-internet-surveys/ 